\title{
The slow growth of a movement
}

\author{
And finally, a journal
}

The issue of tobacco and health has been around for centuries. In 1604 King James I issued his Counterblast to Tobacco, perhaps the most well known indictment of the weed in tobacco lore. He called tobacco use

a custome lothsome to the eye, hatefull to the Nose, harmefull to the braine, dangerous to the Lungs, and in the blacke stinking fume thereof, neerest resembling the horrible Stigian smoke of the pit that is bottomlesse. ${ }^{1}$

In 1856-7 the Lancet published the opinions of 50 physicians on tobacco use, many of whom attributed increased crime, nervous paralysis, loss of intellectual abilities, and visual impairment to tobacco use. ${ }^{2}$

As pointed out in this issue's cover essay, the first clinical report linking tobacco and cancer occurred as early as 1771 , when Dr John Hill of London described six cases of "polypusses" related to "the immoderate use of snuff." " Epidemiological studies in the late 1940s and 1950s documented strong associations between smoking and disease, especially lung cancer. These studies were described in two historic reports: the 1962 report of the Royal College of Physicians of London ${ }^{4}$ and the 1964 report of the US Surgeon General. ${ }^{5}$

The addictive nature of tobacco was recognised early on. ${ }^{6}$ In 1623 Sir Francis Bacon wrote: "The use of tobacco is growing greatly and conquers men with a certain secret pleasure, so that those who have once become accustomed thereto can later hardly be restrained therefrom.""7 Research on the pharmacological actions of nicotine began in the late $1800 \mathrm{~s}$, including the classic work by Langley and Dickinson on nicotine's effects on autonomic ganglia. ${ }^{8}$ Several decades of modern investigation led to the comprehensive 1988 report of the Surgeon General on nicotine addiction. ${ }^{9}$

More than 50000 articles on tobacco and health have now been published in the biomedical literature, the findings of which have been reviewed in more than 8000 pages of 21 reports from the Surgeon General. ${ }^{10}$ In the preface to her 1990 report Surgeon General Antonia Novello concluded that "smoking represents the most extensively documented cause of disease ever investigated in the history of biomedical research."11 As the British Medical Association proclaimed, "the battle over the evidence has been won"; thus, research on tobacco and health has shifted from investigations into the health effects of tobacco use to analyses of smoking behaviour and evaluations of tobacco control interventions. ${ }^{12}$

In the 1970s and 1980s "tobacco and health" developed into a movement. As the first issue of this journal was sent to subscribers the eighth world conference on tobacco or health began in Argentina. More than 1000 researchers, educators, and tobacco control advocates attended the seventh world conference (1990) in Perth, Australia, where more than 285 papers were presented. ${ }^{13}$ Many government health agencies have offices on tobacco and health. Many health organisations have programmes, committees, and staff dedicated to this endeavour. Tobacco control legislation has become much more prevalent around the world. ${ }^{1415}$

Yes, interest and activity in this field have grown substantially. Nevertheless, interest and activity in this field are far below what they should be given the enormity of the tobacco problem. It is baffling, for example, that it took so long for a journal on tobacco control to be launched - 388 years after King James's Counterblast and 30 years after the Royal College of Physicians' first report. By contrast, several journals devoted to AIDS $^{16-18}$ were launched six or so years after the first published description of the acquired immunodeficiency syndrome. ${ }^{19}$ Does it make sense that the yearly world conferences on AIDS attract 8000 participants, ${ }^{20}$ whereas the biennial world conferences on tobacco and health attract 1000 ?

Despite its slow growth, the field of tobacco and health has a lot going for it. There is no shortage of horrifying statistics to justify working in this area. For those who seek challenges, we are fighting a deadly, additive behaviour supported by a wealthy and powerful industry. The people who work in this area are extremely committed to and passionate about their work.

Our problems include lack of resources and an inadequate coordination of activities. Our goals are often disparate and our efforts are fragmented-and fragmentation seems to be increasing. The definition of "movement" is instructive:

... a diffusely organized or heterogenous group of people or organizations tending toward or favoring a generalized common goal.... ${ }^{21}$ [my italics]

The movement is diffuse and it often stumbles toward its goals. And whereas we agree on the general goal of reducing tobacco related disease, how best to achieve that objective is a matter of ongoing debate.

Tobacco Control will not be able to ameliorate the problem of scarce resources. However, my hope is that it will help foster communication, cooperation, and cohesion among the many organisations and individuals working in this field. I also hope the journal can enhance the esteem of the movement, to help it attract a more abundant supply of educators, advocates, and researchers. 
Similar to the control of infectious diseases, the prevention and control of tobacco use require an understanding of the causative agents (tobacco products), the vectors (those who manufacture, advertise, distribute, and sell tobacco products), the host, and the environment. ${ }^{10} \mathrm{As}$ such, Tobacco Control will report on:

- The nature and extent of tobacco use worldwide

- The effects of tobacco use on health, the economy, the environment, and society

- The efforts of the health community and health advocates to prevent and control tobacco use

- The activities of the tobacco industry and its allies to promote tobacco use.

The journal will, above all, publish research articles that have undergone rigorous peer review. Research areas will include:

- The evaluation of smoking prevention and cessation programmes

- The tracking and evaluation of tobacco control policies and legislation

- Epidemiological and behavioural research on tobacco use

- The health effects of smoking, smoking cessation, passive smoking, and smokeless tobacco use.

Consistent with these emphases, this first issue contains research articles on workplace smoking policies, ${ }^{223}$ tobacco advertising, ${ }^{24}$ and physicians' advice to patients on stopping smoking. ${ }^{25}$ A special contribution reviews tobacco litigation in 1991, analysing cases in Canada, Australia, and the United States. ${ }^{26}$ Two letters and a book review address strategies to prevent young people taking up smoking. Tobacco industry activities are covered in the news section and in Ad Watch (p 49), Industry Watch ( $p$ 50), and elsewhere. And because of the tragic edge to this issue, Tobacco Control includes a column called The Lighter Side ( $p$ 48), which will afford readers a bit of comic relief by reproducing anti-tobacco cartoons.

As indicated in the subtitle of the journal's name, Tobacco Control is an international journal. The editor, deputy editor, and technical editor reside in the United States, Australia, and the United Kingdom, respectively. Regional and associate editors and members of the Editorial Advisory Board represent 30 countries throughout the world.

Above all, the content of the journal will be international in scope. The stamps on the front cover come from eight countries encompassing all six regions of the world (according to the World Health Organisation's classification system). The inside of the journal includes contributions from Argentina, Australia, Belgium, France, Hong Kong, India, the Netherlands, the People's Republic of China, Peru, Switzerland, the United Kingdom, and the United States. Abstracts of full length articles are translated into Spanish, French, and Chinese, courtesy of the Pan American Health Organisation, the European Bureau for Action on Smoking Prevention, and the Chinese National Institute of Health Education.

I aim for this journal to be a vehicle for progress in tobacco control worldwide. The international flavour of Tobacco Control should expand in future issues. I am optimistic these ambitious goals can be achieved given the enthusiastic response the journal has already received. That enthusiasm can be measured by the number and diversity of individuals and organisations that have agreed to become involved in the journal (see inside front cover), and by the material already submitted to Tobacco Control. The editors welcome your contributions and ideas on how this publication can best serve the field of tobacco control.

Editor RONALD M DAVIS

1 [James I, King of Great Britain]. A counterblast to tobacco. London: R[obert] B[arker], 1604 .

What are the effects of smoking upon the human frame? [Editorial.] Lancet 1857 March 14: 270-1. 3 Redmond DE. Tobacco and cancer: the first clinical report, 1761 . N Engl
f Med 1970; 282: 18-23.

Royal College of Physicians. Smoking and health. Summary and report of the
Royal College of Physicians of London on smoking in relation to cancer of the lung and other diseases. New York: Pitman Publishing, 1962.

5 US Department of Health, Education, and Welfare. Smoking and health. Report of the Advisory Committee to the Surgeon General of the Public Health Service. Atlanta, Georgia: Public Health Service, Centers for Disease Control, 1964. (PHS Publication No 1103.)

6 Brecher EM. Licit and illicit drugs: the Consumers Union report on narcotics, stimulants, depressants, inhalants, hallucinogens, and marijuana-including caffeine, nicotine, and alcohol. Boston: Little, Brown, 1972: 209-13.

7 Bacon F. Historia vitae et mortis (1623). Cited by Corti EC. A history of smoking (translated by P England). London: George G Harrap, 1931:69.

8 Langley JN, Dickinson WL. On the local paralysis of the peripheral ganglia and on the connexion of different classes of nerve fibres. with them. Proceedings of the Royal Society of London 1889; 46: 423-31.

9 US Department of Health and Human Services. The health consequences of smoking: nicotine addiction. A report of the Surgeon General, 1988. Atlanta, Georgia: Centers for Disease Control, Office on Smoking and Health, 1988. (DHHS Publication No (CDC) 88-8406.)

10 Davis RM, Smith R. Addressing the most important preventable cause of

death: a new journal on tobacco control. BMF 1991; 303: 732-3.
11 US Department of Health and Human Services. The health benefits smoking cessation : a report of the Surgeon General, 1990. Atlanta, Georgia: Centers for Disease Control, Office on Smoking and Health, 1990. (DHHS Publication No (CDC) 90-8416.)

12 US Department of Health and Human Services. Reducing the health consequences of smoking: 25 years of progress. A report of the Surgeon General, 1989. Atlanta, Georgia: Centers for Disease Control, Office on Smoking and Health, 1989. (DHHS Publication No (CDC) 89-8411.)

13 Durston B, Jamrozik K, eds. Tobacco and Health 1990: the global war. Perth: Health Department of Western Australia, 1990. (Proceedings of the seventh world conference on tobacco and health.)

14 Roemer R. Recent developments in legislation to combat the world smoking epidemic. Geneva: World Health Organisation, 1986. (WHO Publication WHO/SMO/HLE/86.1.)

15 Roemer R. Legislative responses to tobacco use. Dordecht: Martinus Nijhoff, 1991.

16 Quist N. AIDS and public policy: publisher's introduction. AIDS and Public Policy fournal 1986; 1: 1-2.

17 Adler MW, Weber JN. Editorial. AIDS 1987; $1: 1$

18 Haseltine WA, Volberding PA, Blattner WA. Editorial. $f$ Acquir Immune Defic Syndr 1988; $1: 1$.

19 Centers for Disease Control. Pneumocystis pneumonia-Los Angeles. $M M W R$ 1981; 30: 250

20 Altman LK. US ban of infected travelers attacked at world AIDS conference. New York Times 1991, June 17: A13.

21 The Random House dictionary of the English language. Unabridged ed. New York: Random House, 1967.

22 Eng TR, Emont SL, van der Vlugt TH. Support for restricting smoking at workplaces in developing countries: a survey of Peace Corps staff. Tobacco Control 1992; 1 : 13-8.

23 Borland $R$. Changes in prevalence of and attitudes to restrictions on smoking in the workplace among indoor workers in the state of Victoria, Australia, 1988-90. Tobacco Control 1992; 1: 19-24.

24 Warner KE, Goldenhar LM. Targeting of cigarette advertising in US magazines, 1959-86. Tobacco Control 1992; 1: 25-30.

25 Gilpin E, Pierce J, Goodman J, Giovino G, Berry C, Burns D. Trends in physicians' giving advice to stop smoking, United States, 1974-87. Tobacco Control 1992; 1: 31-6. 26 Daynard RA. Recent developments in tobacco litigation: 1991. Tobacco
Control 1992; 1: 37-45. 